Discussion Paper No. 14-010

\title{
Idiosyncratic Risk and the
} Cost of Capital The Case of Electricity Networks

Dominik Schober, Stephan Schaeffler, and Christoph Weber

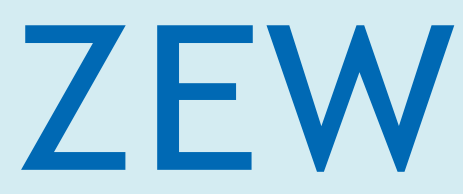

Zentrum für Europäische Wirtschaftsforschung $\mathrm{GmbH}$ Centre for European Economic Research 
Discussion Paper No. 14-010

\title{
Idiosyncratic Risk and the Cost of Capital - The Case of Electricity Networks
}

\author{
Dominik Schober, Stephan Schaeffler, \\ and Christoph Weber
}

Download this ZEW Discussion Paper from our ftp server:

http://ftp.zew.de/pub/zew-docs/dp/dp14010.pdf

Die Discussion Papers dienen einer möglichst schnellen Verbreitung von neueren Forschungsarbeiten des ZEW. Die Beiträge liegen in alleiniger Verantwortung der Autoren und stellen nicht notwendigerweise die Meinung des ZEW dar.

Discussion Papers are intended to make results of ZEW research promptly available to other economists in order to encourage discussion and suggestions for revisions. The authors are solely responsible for the contents which do not necessarily represent the opinion of the ZEW. 


\title{
IdIOSYNCRATIC RISK AND THE COST OF CAPITAL - THE CASE OF ELECTRICITY NETWORKS ${ }^{1}$
}

\author{
SCHOBER $^{*, * * *,}$, Dominik; SCHAEFFLER ${ }^{* *}$, Stephan; WEBER $^{* * *}$, Christoph \\ * ZEW Centre for European Economic Research and MaCCI, L7,1, 68161 Mannheim, Germany \\ ${ }^{* *}$ Horvàth \& Partners Management Consultants, Ganghoferstr. 39, 80339 Munich, Germany \\ ${ }^{* * *}$ Chair of Management Science and Energy Economics, University of Duisburg Essen, Universitätsstr. 12, \\ 45117 Essen, Germany \\ † Corresponding author; Email: schober@zew.de
}

\begin{abstract}
We analyze the treatment and impact of idiosyncratic or firm-specific risk in regulation. Regulatory authorities regularly ignore firm-specific characteristics, such as size or asset ages, implying different risk exposure in incentive regulation. In contrast, it is common to apply only a single benchmark, the weighted average cost of capital (WACC), uniformly to all firms. This will lead to implicit discrimination. We combine models of firm-specific risk, liquidity management and regulatory rate setting to investigate impacts on capital costs. We focus on the example of the impact of component failures for electricity network operators. In a simulation model for Germany, we find that capital costs increase by approximately 0.2 to 3.0 percentage points depending on the size of the firm (in the range of $3 \%$ to $40 \%$ of total cost of capital). Regulation of monopolistic bottlenecks should take these risks into account to avoid implicit discrimination.
\end{abstract}

Keywords

Idiosyncratic/firm-specific risk; discrimination; incentive-based and quality regulation; liquidity management; size effects; electricity networks

JEL-Classification: G32, G33, L51, L94

\footnotetext{
${ }^{1}$ For useful discussions on earlier versions of the paper, the authors want to thank the participants of the $29^{\text {th }}$ Annual Eastern Conference of the Rutgers Center for Research in Regulated Industries, especially Howard Spinner and Kathleen King, as well as the participants of the $8^{\text {th }}$ Conference on Applied Infrastructure Research at the TU Berlin and the $2^{\text {nd }}$ Annual Competition and Regulation in Network Industries Conference in Brussels. We also would like to thank the participants of an internal workshop at the ZEW in Mannheim, especially Konrad Stahl and Oliver Woll. Remaining errors are solely ours.
} 


\section{INTRODUCTION}

In regulation it is common that the costs of equity capital only include compensation for the systematic rather than also the unsystematic risk incurred by the regulated firm's shareholders. ${ }^{2}$ They are assumed to diversify their portfolios perfectly, allowing them to ignore the latter type of risk. ${ }^{3}$ Financial distress costs, however, may arise from imminent insolvency or illiquidity caused by unsystematic (or idiosyncratic) risks, making it optimal for a firm to engage in costly hedging. The acknowledgement of resulting costs, in contrast to regulatory practice, is then essential.

A major rationale behind this argument is the need for liquidity management to obviate costly insolvency or bankruptcy. An unregulated automobile manufacturer, for example, would include these costs in its overall profit maximization and determine a hurdle rate higher than capital costs to compensate for firm-specific risks eventually incurred. These may equally depend on the riskiness of single projects or portfolio composition. In an unregulated market, a competitive equilibrium outcome would therefore consider costs arising from idiosyncratic risks. It is then a logical consequence to acknowledge occurring transaction costs in a regulated market, compensating firms properly for bearing corresponding risks and related costs. Furthermore, this is independent of the choice between either cost plus or incentive regulation regimes. Under rate of return or total cost based rate regulation, firm-specific risk is usually borne by the customer on the basis of a "used-and-useful" criterion when an actual loss is incurred. In other words, this is a cost rollup, which attenuates visibility to the regulator and disguises risk-induced costs. In contrast, pure price or revenue-based rate regulation ${ }^{4}$ will make idiosyncratic risk directly visible through firms' additional spending on costly hedging. One classic example for a regulated industry is the operation of electricity networks. An operator faces some important sources of idiosyncratic risks related to uncertainty regarding the unforeseeable, stochastic failure of its production assets. For example, the relative importance of this risk will depend on the firm's network size. ${ }^{5}$ Given the law of large numbers, bigger network operators will have a relatively lower risk exposure than smaller operators. The latter will consequently have to spend relatively more on their liquidity management activities and suffer an economic disadvantage even when the average cost of the pure operation of the network is the same. ${ }^{6}$ The consequence in this example is that the regulatory process may discriminate against smaller firms in the presence of such idiosyncratic risk. It is also observable in practice that smaller firms typically complain of increased pressure due to the relatively high stochasticity of cash flows after the introduction of incentive regulation. In a broader context, the costs of capital markups linked to size effects (and granted by the market) are found to be significant. For example, Banz (1981) and Fama and French $(1995,1997)$ find substantial average systematic risk premia for smaller firms in general. Adding to this evidence, in a study focusing on electricity network operators, Schaeffler and Weber (2013) find a significant size-related risk premium. So far, explanations of these empirically observable effects have focused on capital-raising economies through risk

\footnotetext{
${ }^{2}$ Idiosyncratic risk is also known as unsystematic, firm-specific or firm-dependent risk.

${ }^{3}$ Following this rationale, the costs of equity capital are then calculated using well-known models, such as the capital asset pricing model, the three-factor model, or the arbitrage pricing theory.

${ }^{4}$ Guthrie (2005) uses this more correct term of "pure price or revenue based rate regulation" rather than the widely known but less exact term "incentive regulation."

${ }^{5}$ Also, other firm characteristics may systematically impact the failure behavior of assets, e.g., differences in asset age structure. The term "failure behavior" describes the stochastic properties of the production assets in place, such as the distribution law they follow, its moments and how this distribution law depends on size characteristics, or, for example, on age structure characteristics.

${ }^{6}$ Size effects due to the stochasticity of failure events correspond to some form of economies of scale due to the law of large numbers. Yet, they differ from economies of scale effects usually discussed in the context of firm size and, to our knowledge, have not been discussed in the previous literature. Huettner and Landon (1978), Roberts (1998), and Filippini (1998) present evidence with regard to economies of scale linked to network size from density effects in the production function, which have an impact on average costs. However, they do not consider the impact of network size on risk.
} 
reduction in the part of a firm's equity that covaries with a market portfolio. ${ }^{7}$ In contrast, the focus in this article is on the impact firm size may have on idiosyncratic risk on the production side and the resulting impact on possible financial distress. This is not linked to any covariation with a market portfolio but nevertheless involves additional costs.

The aim of this article is therefore to demonstrate the effects of the regulator neglecting idiosyncratic risk. Both the regulatory framework and physical failure are investigated in an analytical model. Resulting capital cost markups are derived. Furthermore, a simulation study based on German electricity network regulation gives insights into differences in idiosyncratic risk exposure and their impact on capital costs. Calculated markups are compared to actual current capital cost and found to be significant. Ignoring these differences is thereby shown to raise implicit discrimination issues.

The contributions of this article are fourfold. First, a sound framework is developed to assess the impact of idiosyncratic risk in production on capital cost via an analysis of the liquidity management decision (section 2). In line with Holmström and Tirole (2000), who investigate the nexus of investment optimization, risk and liquidity management, liquidity management here is assumed to take place after investments have been made. ${ }^{8}$ The sequential investmentliquidity management assumption also corresponds to business practice, where two separate organizational units are typically responsible for reinvestment and liquidity management. For liquidity management, the model used in this article notably includes bank lines of credit ${ }^{9}$ as an instrument. As these contain an upfront fee that will later reduce negative cash flows and thereby overall cash flow variation, they have clear similarities to costly hedges. Second, an analytical model of the size-dependent idiosyncratic risk source is used to derive the key result that risk exposure decreases with firm size (section 3). An analytical stochastic stationary state model of network operation with perfect replacement is used to investigate the effects of size on expected costs, standard deviation of costs and the coefficient of variation as a scale-neutral risk measure. Other important cost drivers such as supply conditions (differences in load, density and so forth) are omitted to clearly demonstrate the riskdecreasing effect of firm size. Third, a Monte Carlo simulation based on representative data from more than 800 German electricity network operators is used to estimate the empirical relevance of idiosyncratic risks (sections 4 and 5). A detailed network representation and empirically estimated failure rates are used to obtain valuable and conservative estimates of risk exposure. Fourth, by coupling the network replacement investments and resulting risk exposures with the previously developed financial and liquidity management models, the impact on capital costs is evaluated (section 6). ${ }^{10}$ This provides clear indications for regulators on how to account for size effects in price, revenue or rate of return regulation. Section 7 concludes the article.

\footnotetext{
${ }^{7}$ See Scherer and Ross (1990) for a detailed discussion of this and other types of economies of scale. However, these authors also do not consider the indirect type of economies of scale related to reduced idiosyncratic risk and the corresponding lower need for liquidity buffers.

${ }^{8}$ In contrast to the theoretical model of Holmström and Tirole (2000), we exclude hedging (in its classic sense) after the investment decision has been made. Network operators cannot hedge their idiosyncratic risk using traded financial securities. Some hedging, in the form of insurance contracts, can be envisaged in principle. However, so far only limited activities are empirically observable. Moreover, asymmetric information concerning asset states and moral hazard constitute serious problems for a well-functioning secondary market (cf., e.g., Caillaud et al. 2000, who discuss the relevance of costs from asymmetric information in the context of insurance-equivalent to a loan commitment-and debt contracts.

${ }^{9}$ Bank lines of credit are also known as revolving credit facilities or loan commitments.

${ }^{10}$ Analyzing the impact on liquidity management is certainly only one option in demonstrating the possible monetary consequences of additional uncertainty from idiosyncratic risks. It is the alternative of choice in this article because the necessary assumptions for the calculation of liquidity management costs are the least strict and most empirically attestable. Liquidity management in this context is understood as the optimal decision to secure the going concern in possible illiquid states and prevent financial distress. It thereby minimizes expected costs, including distress costs, given a certain distribution of stochastic cash flows resulting from investment decisions. Hedging is complimentary to liquidity management as it is usually understood as a (not necessarily costly) activity to modify the original cash flow distribution.
} 


\section{IDIOSYNCRATIC RISK, CAPITAL COSTS AND REGULATION}

\section{i. Relevance of Idiosyncratic Risk for Regulation}

Most regulators solely consider systematic risk by granting equity returns on the regulated asset base, e.g., by employing the capital asset pricing model (CAPM). ${ }^{11}$ The CAPM is in widespread use and is applied by a multitude of regulators. For example, Schaeffler and Weber (2013) investigate risk premia for electric utilities and state that the vast majority of European regulators (all of the 19 countries investigated) use the CAPM, refraining from the inclusion of any idiosyncratic risk components. ${ }^{12}$ Other models, such as the three-factor model (TFM) or the arbitrage pricing theory (APT), have been proposed to estimate systematic risk premia. ${ }^{13}$ Like the CAPM, they have been suggested to estimate systematic, undiversifiable risk exposure, i.e., the degree of covariation between firms' equity values and market portfolios. The former model tries to do this by categorizing firms, e.g., in relation to size or book-to-market ratio, whereas the latter tries to find statistically relevant explanations for equity variation by adding macroeconomic factors (e.g., inflation, business cycle state). In the special case of electricity and telecommunications utilities, Fama and French (1992) derive slightly negative risk premia for smaller firms in contrast to the findings and arguments in this article. Especially in the German case investigated in sections 4 to 6 , neither a systematic nor an idiosyncratic risk premium is granted in practice.

In contrast, variation in equity value due to idiosyncratic risk is by definition not correlated to a market portfolio. Therefore, firm-specific risk is considered irrelevant for investors as they are supposedly able to diversify optimally in the absence of any transaction or liquidity constraints. However, several market imperfections make idiosyncratic risk costly-and consequently also provide an incentive for hedging. In the context of optimal (external) financing, Froot et al. (1993, p.1633) state that “...hedging is beneficial if it can allow a firm to avoid unnecessary fluctuations in either investment spending or funds raised from outside investors." The authors further point out several rationales for hedging idiosyncratic risk. One of the central arguments for costly hedging is the risk of insolvency or bankruptcy. The obviation of firm liquidation makes liquidity management necessary, which in turn comes at a cost. If volatile earnings expose the company to a significant risk of running into illiquidity, risk mitigation may be rational to obviate the potentially higher costs of resultant financial distress. These costs are substantial and comprise high transaction costs from possible insolvency or bankruptcy, ${ }^{14}$ but most importantly include the increased costs of refinancing because of an ex ante higher probability of bankruptcy. This may also lead to a downgrading in rating. ${ }^{15}$ Whereas the direct costs of financial distress seem to be small (e.g., litigation fees), the indirect costs, such as loss of market share, inefficient asset sales or lost investment opportunities, appear to be more pronounced. ${ }^{16}$ These transaction costs will then entail the convexity of financing costs. The more pronounced the firm-specific risks, the greater the incentive for hedging and the ensuing expected cost of hedging and cost of capital. This and

\footnotetext{
${ }^{11}$ See, e.g., Sharpe (1964) inter alia.

12 This study includes all major European countries as well as New Zealand and Australia. Among these, only Kosovo provides a supplementary premium of $1.3 \%$ for size differences.

${ }^{13}$ See Fama and French (1992) on the TFM and Ross (1976) on the APT.

${ }^{14}$ In general, bankruptcy costs may range from approximately $10 \%$ to $25 \%$ of firm value (see, e.g., Bris et al. 2006, who analyze the depreciation of book values of 286 companies during their bankruptcy processes). Reimund et al.’s (2008) study of 46 German DAX companies draws on analysts' forecasts concerning market values and similarly determines a depreciation of approximately $28 \%$ on average, but up to $44 \%$ of the enterprise value in extreme cases.

15 Almeida and Philippon (2007) complement the literature on the value of financial distress using the probabilities of bankruptcy, which are conditional on the state of the economy. As financial distress is more likely to occur in periods of economic downturn, the probability of experiencing distress increases more than threefold in some cases, i.e., from approximately $1.4 \%$ of the NPV of a firm pre distress to approximately $4.5 \%$ for a BBB-rated firm. The authors state that the value of distress can be as important as marginal tax benefits.
}

${ }^{16}$ See, e.g., Opler and Titman (1994) and Shleifer and Vishny (1992). 
some other arguments based on market imperfections ${ }^{17}$ rationalize hedging and spending for liquidity provision in the light of idiosyncratic risk. Furthermore, in the context of infrastructure regulation, sunk costs and regulatory discretion over cash flows make idiosyncratic risk directly relevant to the firm. Brennan and Schwartz (1982) show that firmspecific risks increase capital costs under historical cost-based regimes until the regulator approves costs in the next hearing. Evans and Guthrie (2005) show that idiosyncratic risks will increase capital costs also in price-based replacement cost standard incentive regulation regimes by post hoc (after hearings) cash flow adjustments. They investigate the effects of demand and replacement cost fluctuations when investments are irreversible. If regulators do not account for these firm-specific risks, the regulated companies might not break even in the long run. The introduction of price or revenue-based regimes often makes idiosyncratic risks transparent, whereas under cost-based regimes such risks are usually borne by the customer on the basis of a "used-and-useful" regulation.

The risks caused by stochastic failures triggering replacement costs and possibly quality penalties are an important part of these idiosyncratic risks. Stochastic asset failure directly influences the company's cash flows. The next subsection demonstrates how this risk can correctly be considered in a regulatory price setting.

\section{ii. Liquidity Management and Capital Cost with Idiosyncratic Risk}

The total return risk of a firm can be separated in a systematic part and an idiosyncratic part. With $r$ being the rate of return for a network operator, ${ }^{18} r_{f}$ and $r_{m}$ being the risk-free return and the return of the market portfolio, $\beta$, being the ratio of the covariance of the returns to the network operator and the market portfolio and the variance of the return on the market portfolio, and $\varepsilon$ the risk in returns from idiosyncrasies, the return of a company may be written as:

$$
r=(1-\beta) r_{f}+\beta r_{m}+\varepsilon .
$$

As network firms are small-as is the whole network infrastructure sector-compared to the entire economy, idiosyncratic risks will barely influence the market return or the market price of risk. Nevertheless, idiosyncratic risks do matter from a private firm perspective. In particular, the costs of financial distress provide a clear incentive for the firm to engage in risk and liquidity management activities and induce additional costs. As concluded by Froot et al. (1993), hedging comes at a certain cost and that cost will have to be recognized by a regulator to ascertain the potential for refinancing and thereby participation as well as efficient behavior by the regulated agent. In many regulatory regimes in which a WACC is applied to a regulatory asset base, this condition is not fulfilled.

Before entering into a detailed discussion of the implications for the regulatory design, a valid model for quantifying the costs of idiosyncratic risk is needed. The focus is thus on the costs of liquidity management as these are the least tied to strong assumptions and also most obviously lead to additional costs. ${ }^{19}$ Liquidity management will then either imply additional expenses $M_{0}$ for costly hedging and/or an additional capital buffer $B$ to avoid financial distress. From the point of view of the network firm, the actual rate of return also depends on

\footnotetext{
${ }^{17}$ Other reasons for market imperfections and therefore engaging in costly hedging include the imperfect diversification of agents, who hold a significant share of their wealth in the firm (see Stulz, 1984; Smith and Stulz, 1985), moral hazard calling for an effort-inducing rent guaranty to the agent making hedging necessary (see Holmström and Tirole 1998, 2000; Tirole 2005) or asymmetric information concerning the agent's performance, when volatile results could be misinterpreted as arising from a lack of effort or incompetence. A final reason might simply be convex taxation functions, which lower earnings when losses cannot be carried forward to other periods (see Froot et al. 1993).

${ }^{18}$ We focus on the return on the total asset base disregarding the question of the optimal long-term capital structure (on this issue, see Schaeffler 2012).

${ }^{19}$ Costs resulting from other hedging motives are in general more difficult to assess because of observability and quantification problems. This is notably the case for the risk aversion assumed in the frameworks of Froot and Stein (1998) and Holmström and Tirole (2000). Nevertheless, the estimates obtained from subsequent calculations have to be interpreted as lower boundaries for costs induced by idiosyncratic risks.
} 
the incoming cash flows $Y_{i}$, the outgoing (other) cash flows $Y_{0}$ and the conventional asset base $A$, i.e. the so-called "regulatory asset base" given by the following equation: ${ }^{20}$

$$
r=\frac{Y_{i}-Y_{o}-M_{0}}{A+B}
$$

The hedging cost of liquidity management is then summed as $M=M_{0}+E[r] B$ including current expenses $M_{0}$ for, e.g., the use of revolving credit facilities, short-term capital acquisition or insolvency and the costs of additional capital $B$. Capital $B$ can be employed at the cost of capital rate $r$. When an agent receives an incentive-compatible contract, the corresponding expected firm value $V$ will be maximized thus:

$$
\max V=Y_{i}-Y_{o}-E[r] A-M
$$

The incoming cash flows $Y_{i}$ are determined by the transported electricity $\omega$ and the network tariffs $R$, which are assumed to be exogenously given. Temporary deviations in the quantity $\omega$ (e.g., demand fluctuations) add to the stochasticity of incoming cash flows. Thus:

$$
Y_{i}=R \cdot \omega .
$$

The outgoing expenses consist of expenses for planned replacement $C$, for unplanned replacement $S$ and all other costs $Q$ and the opportunity costs of holding capital to finance the regulatory asset base $A:^{21}$

$$
Y_{o}=C+S+Q
$$

A network firm has several options in relation to facing potential liquidity shortages and minimizing liquidity management costs $M$. First, and most simple, it could take up capital in advance to ensure sufficient sources in the case of need. However, holding cash for capital buffers $B$ implies opportunity costs. Second, it could secure bank lines of credit $L-B$. Third, it could "wait and see" and raise capital in the short-term.

The advantages and the relevance of these different options are discussed extensively in the literature, on theoretical as well as empirical grounds. Acharya et al. (2007) show that it is optimal for financially constrained firms to transfer cash from high cash flow states to low ones to finance more profitable projects later. In their words, cash thus is not negative debt and cash will be preferred to debt. Flipping the coin, in a later article, Acharya et al. (2009) relate their arguments to the aggregate risk exposure of a firm. Firms with high systematic risk will have problems and find it too expensive to satisfy their liquidity demand in times of sparse liquidity in the entire economy and thus rely more heavily on cash than firms with low systematic risk. Demiroglu and James (2011) survey (mostly) empirical literature and find results on the substitutability of cash and debt or credit lines to be contradictory. There is some evidence that in having a line of credit, the marginal value of cash is lower. On the other hand, financially constrained firms are found to associate a positive marginal value with both cash and credit lines, which implies that both are necessary. Relatively unconstrained firms, by contrast, rely on credit lines (see Flannery and Lockhart 2009).

We thus give the firm the choice between up-front liquidity provision through cash and credit lines or ex post replenishment through short-term action. This approach is similar to that adopted by Disatnik et al. (2010). They analyze the use of exchange rate derivatives for cash flow hedging and find a positive effect of hedging on the relative use of bank lines of credit compared to cash. Both are thus found to be (imperfect) substitutes, ${ }^{22}$ or, as Kashyap, Rajan and Stein put it in their seminal article of 2002: “deposits and loan commitments offer to bank customers a very similar service: the provision of liquidity on demand to accommodate unpredictable needs” (p. 35). ${ }^{23}$

\footnotetext{
${ }^{20}$ Leverage is treated as exogenous here; on the question of optimal capital structure, see, e.g., the models of Scott (1976) and Bradley et al. (1984). Note that these approaches include potential bankruptcy but do not consider illiquidity problems.

${ }^{21}$ Holding additional capital to finance the liquidity buffer is included in $M$.

${ }^{22}$ Cash flow hedging will reduce the uncertainty in demand for cash, thereby making it easier to satisfy the contingencies of lines of credit. Adding the cost advantage, the authors can analytically and empirically demonstrate a relative increase in the use of credit lines and in firm value.

${ }^{23}$ Holmström and Tirole (1998) add the argument that holding cash is not efficient when adverse cash flow shocks are not highly correlated across firms. It is then more efficient for banks to serve as liquidity pools,
} 
In our model, liquidity management decisions on risk capital $B$ and total liquidity $L$ are made in view of a maximization of the firm value $V$ (cf. equation (3)):

$$
\max _{B, L} E\left[Y_{i}-Y_{o}-r A-M\right]
$$

The cash flows from $Y_{i}$ and $Y_{0}$ and the asset base $A$ and the required return on equity $E[r]$ cannot be influenced by the liquidity management decisions on $L$ and $B$. Writing $x=Y_{i}-Y_{0}$, the problem therefore reduces to:

$$
\max _{B, L} E[-M(B, L, x)]=\min _{B, L} E[M(B, L, x)]
$$

Thus, the expected additional costs of liquidity management are minimized. These include a number of capital cost parameters depending on the source chosen. Holding liquidity buffers through up-front capital provision $B$ at cost $r$ is a common option, where $r$ is the opportunity cost of holding capital, i.e., the weighted average cost of capital. At the other extreme, shortrun capital replenishment can be used to balance ex ante uncovered capital needs. Short-run replenishment necessitates a supplement of $u$ over the usual cost of capital $r$, which totals $r+$ $u$. This might well include the eventuality of bankruptcy. As a third possibility, the firm may choose bank lines of credit. The prices for this option consist of two parts: a variable commitment fee $s_{1}$ for an option to take the bank lines of credit up to an amount of $B-L$ and a second variable part for actual usage at an additional supplementary cost $s_{2}$ adding to the capital cost $r$. Thereby, capital provision under this option amounts to $r+s_{2}$.

Thus the following maximization problem arises:

$$
\begin{aligned}
& \max _{B, L}[-M(B, L, x)] \\
& =\max _{B, L}\left[\int_{-\infty}^{-L}[(x+L)(r+u)] f(x) d x+(B-L) s_{1}+\int_{-L}^{-B}\left[(x+B)\left(r+s_{2}\right)\right] f(x) d x-B r\right]
\end{aligned}
$$

Under the assumption of normally distributed cash flows $x$, the optimization with respect to the two decision variables $B$ and $L$ becomes analytically tractable. First order conditions lead to the following two necessary conditions for the optimal solution: ${ }^{24}$

$$
F(-B)=F(-L)+\frac{r-s_{1}}{r+s_{2}} \quad L=B+\frac{(r+u) F(-L)-s_{1}}{\left(r+s_{2}\right) f(-L)}
$$

These equations only allow solution by numerical methods; nevertheless, inspection reveals some regularities in line with intuitive expectations. According to the first condition, a notable increase in $s_{1}$ or $s_{2}$ obviously leads to a rapprochement of $L$ and $B$, which means that when lines of credit become more expensive, they will be sourced to a lesser extent. In contrast, an upward shift in $r$, which makes risk capital provision more expensive, will make lines of credit relatively less expensive and thus making their extension profitable. This approach will be used to compute capital buffers and lines of credit empirically in section 6. Then, the additional costs resulting from idiosyncratic risk may be expressed as risk premia on top of the rate of return required for the regulatory asset base.

Summarizing the arguments thus far, specific risk stemming from the stochasticity of the production function should play a more important role in regulation. The following section provides a cash flow model of network replacement, permitting the identification of cash flow risks due to the network structure.

\section{ANALYTICAL MODEL OF SPECIFIC FAILURE RISK}

Consider a network operator under quality regulation that optimizes its replacement strategies. ${ }^{25}$ The costs considered correspond to the capital expenditure for replacement of

issue liquidity insurance, and provide liquidity only to firms that receive liquidity shocks. As a result, credit lines will be a more efficient means of providing liquidity.

\footnotetext{
24 The derivation of these solutions is contained in Appendix I.
}

${ }^{25}$ Similar to Markowitz (1952), costs and the risk measure are treated separately. Combining the two can be seen as a portfolio menu from which the optimizing network operator is able to choose. A constant level of risk aversion is assumed, which would have to be adjusted for different levels of risk aversion when applied by an authority. 
equipment, $C$, and the supplementary cost for premature replacement as well as penalties for not delivering the quality expected by grid customers, $S .{ }^{26}$ The decision variables are the replacement ages $t_{j}$ at which asset $j$ is subject to planned replacement. In order to keep the problem analytically tractable, we choose a stationary setting and focus on the equilibrium state. ${ }^{27}$ Thus, time in our model is represented by the index $t$ (which can be considered equivalent to the asset age) and the replacement age $t_{j}{ }^{28}$ The failure probability of an asset depends on its conditional failure rate $r(t)$, the probability that an asset fails once it has reached age $t$. This is related to its unconditional failure rate $f(t)$ and its cumulative survival distribution $1-F(t)$ through:

$$
\begin{aligned}
& f(t)=d F(t) / d t \\
& r(t)=\frac{f(t)}{1-F(t)}
\end{aligned}
$$

Another expression necessary to identify the optimal replacement age in a stationary state is given by the expected utilization period $G\left(t_{j}\right)$. This corresponds to:

$$
G\left(t_{j}\right)=\int_{0}^{t_{j}}(1-F(t)) d t
$$

$G\left(t_{j}\right)$ and the cumulative survival distribution $1-F(t)$ are required to identify the lifetime distribution $H\left(t, t_{j}\right)$ that will occur in the stationary state. Thereby, $G\left(t_{j}\right)$ is normalized by dividing it by $D_{\text {ref }}$, the time unit used for measuring $t$ and $t_{j}$ :

$$
H\left(t, t_{j}\right)=\frac{1-F(t)}{G\left(t_{j}\right) / D_{r e f}}
$$

Equipment that fails has to be replaced, which leads to the differentiation of planned replacement $R_{\text {norm }}$ (due to the fact that the asset's age attains the decision variable replacement age, thus $t=t_{j}$ ) and premature replacement $R_{\text {prem }}$ (due to failure while $t<t_{j}$ ). Premature replacement is given by:

$$
R_{\text {prem }}\left(t_{j}\right)=\int_{0}^{t_{j}}\left(H_{j}\left(t ; t_{j}\right) \cdot r(t)\right) d t=\int_{0}^{t_{j}}\left(\frac{1}{G_{j}\left(t_{j}\right) / D_{\text {ref }}} \cdot f(t)\right) d t=\frac{F\left(t_{j}\right)}{G\left(t_{j}\right) / D_{\text {ref }}}
$$

Planned replacement can be calculated as follows:

$$
R_{\text {norm }}\left(t_{j}\right)=H\left(t_{j}, t_{j}\right)=\frac{1-F\left(t_{j}\right)}{G\left(t_{j}\right) / D_{\text {ref }}}
$$

With $K$ corresponding to the unit costs for replacement, the replacement costs add up to:

$$
C\left(t_{j}\right)=K \cdot\left(R_{\text {prem }}\left(t_{j}\right)+R_{\text {norm }}\left(t_{j}\right)\right)=\frac{K}{G\left(t_{j}\right) / D_{\text {ref }}}
$$

The costs related to the supplementary costs for premature replacement and quality penalties depend on network reliability (which is primarily governed by the number of failures and the network structure). For the sake of simplicity, we assume a direct link between the number of failures and the corresponding quality penalties and premature replacement costs. For each failure, a penalty has to be paid to the regulator and extra money has to be spent on immediate measures, the sum of which is s. Thus we can write:

\footnotetext{
${ }^{26}$ The penalty is based on customer failures. Nevertheless, for an identical customer and network structure, this is equivalent to a revenue-based penalty.

${ }^{27}$ This general setting is described in more detail in Weber et al. (2010). However, the regulatory perspective is not addressed in their article.

${ }^{28}$ In the context of this analytical model, the initial (or starting) age of an asset is not of relevance. However, in dynamic models, the initial age structure of equipment is highly relevant in the context of optimization.
} 


$$
S\left(t_{j}\right)=s R_{\text {prem }}=\frac{s F\left(t_{j}\right)}{G\left(t_{j}\right) / D_{\text {ref }}}
$$

In this stationary equivalent-age replacement model, the objective function of a network operator with $n$ assets is given by:

$$
\min _{t_{j}}\left(\sum_{i=1}^{n}\left(\frac{K_{i}+s_{i} F_{i}\left(t_{j}\right)}{G\left(t_{j}\right) / D_{\text {ref }}}\right)\right)
$$

Assuming an optimization for $n$ identical assets, the network operator's objective function is given by: ${ }^{29}$

$$
\min _{t_{j}}\left(C\left(t_{j}\right)+S\left(t_{j}\right)\right)=\min _{t_{j}}\left(\frac{n K+n s F\left(t_{j}\right)}{G\left(t_{j}\right) / D_{\text {ref }}}\right)
$$

This implies a simplifying assumption with regard to output prices and quantities. Price and quantity are not strategic variables for the firm in that it cannot influence its own earnings level. Prices and earnings are assumed to be solely determined by the regulator (e.g., in the form of a cap), leaving the firm only with a cost minimization problem including the trade-off between cost savings on the one hand and avoidance of extra cost resulting from premature failure or quality penalization on the other hand. Although they are central in many principalagent frameworks, decisions concerning strategic cost-reducing efforts or investments or participation decisions also have to be ignored to keep this model analytically tractable. It is therefore equivalent to a pure price-based contract with no cost-based share.

By deriving the objective function, the necessary optimality condition for an interior solution is obtained: ${ }^{30}$

$$
\frac{\partial C\left(t_{j}\right)}{\partial t_{j}}+\frac{\partial S\left(t_{j}\right)}{\partial t_{j}}=0 \quad \Leftrightarrow \quad-K_{s}-F\left(t_{j}\right)+r\left(t_{j}\right) G\left(t_{j}\right) / D_{r e f}=0
$$

The existence and uniqueness of the optimum interior solution clearly depend on the increasing failure rate (IFR) characteristic of the density function.

\section{Proposition 1:}

Assuming identical assets, expected total cost $\mu=E\left[C\left(t_{j}\right)+S\left(t_{j}\right)\right]$ will increase monotonically and even proportionally in the number of assets $n$, independently of the shape of the failure density assumed.

\section{Proof:}

Expected premature replacements $n R_{\text {prem }}$ and normal replacements $n R_{\text {norm }}$ lead to expected total costs:

$$
\mu=E\left[C\left(t_{j}\right)+S\left(t_{j}\right)\right]=n\left((K+s) R_{\text {prem }}+K R_{\text {norm }}\right)=n\left(K\left(R_{\text {prem }}+R_{\text {norm }}\right)+s R_{\text {prem }}\right) .
$$

Expected total costs stem from regular replacement and quality penalties. Clearly, costs increase proportionally to $n$.

\section{Proposition 2:}

\footnotetext{
${ }^{29}$ To keep the model analytically tractable, the objective function does not formally incorporate the agent's risk attitude. If one introduces risk attitude in the function, smaller network operators' optimal replacement strategy will deviate from larger operators' strategies as they will attach a higher weight to the risk component in the objective function. This would result in earlier replacements, reducing risk but increasing the expected cost. Overall, a socially suboptimal replacement policy would imply additional costs for smaller operators.

${ }^{30}$ See Weber et al. (2010).
} 
Independently of the characteristics of the failure density function, the variance var $[C+S]$, which constitutes a scale-dependent risk measure, increases monotonically with increasing n. The coefficient of variation $\sigma / \mu$ as a scale-free risk measure decreases monotonically with increasing $n$.

Proof:

Under the assumption of premature failure following a binomial distribution with failure probability $P_{\text {prem }}$, the variance of premature replacements can be calculated as $n P_{\text {prem }}(1-$ $\left.P_{\text {prem }}\right)$. One may note that both $R_{\text {prem }}$ and $P_{\text {prem }}$ are defined by $F\left(t_{j}\right) /\left(G\left(t_{j}\right) / D_{\text {ref }}\right.$, yet this expression has two different interpretations. $R_{\text {prem }}$ represents the share of assets expected to be replaced prematurely in the current year. However, the same expression also describes the cumulative failures which appear until $t_{j}$ divided by the average lifetime of an asset given a certain $t_{j}$. In other words, the expression $\mathrm{F}\left(t_{j}\right) /\left(G\left(t_{j}\right) / D_{\text {ref }}\right.$ may also be interpreted as an average yearly failure probability in the stationary state and will then be denoted by $P_{\text {prem. }}$. The variance of total costs as a function of $P_{\text {prem }}$ is given by

$$
\operatorname{var}[C+S]=(K+s)^{2} n P_{\text {prem }}\left(1-P_{\text {prem }}\right) .^{31}
$$

In this simplified model, premature failure imposes extra (re-)investment costs proportional to $s$. However, variance in total costs stems both from the quality penalty and usual reinvestment costs due to premature failure. ${ }^{32}$ Premature replacement is caused by assets that are younger than $t_{j}$. On the other hand, normal or planned replacement is caused by assets of age $t_{j}$ that are replaced in the usual replacement process. Assuming identical assets, total cost variance follows the binomial distribution law.

Evidently, variance in absolute terms will increase with the number of assets. To obtain a scale-invariant measure of the risk, the increase in variance has to be standardized by expected cost. A meaningful dimensionless risk measure is obtained by normalizing the standard deviation $\sigma$ as the square root of the variance by the expected costs. This ratio, known as the coefficient of variation, makes an assessment of the relative importance of risk possible:

$$
\frac{\sigma}{\mu}=\frac{(K+s) \sqrt{n P_{\text {prem }}\left(1-P_{\text {prem }}\right)}}{n\left((K+s) P_{\text {prem }}+K P_{\text {norm }}\right)}
$$

With regard to the definition of $P_{\text {prem }}$, (22) can be transformed into the following expression, with $K_{s}=K / s$ :

$$
\frac{\sigma}{\mu}=\frac{(K+s) \sqrt{\frac{F\left(t_{j}\right)}{G\left(t_{j}\right) / D_{\text {ref }}}\left(1-\frac{F\left(t_{j}\right)}{G\left(t_{j}\right) / D_{\text {ref }}}\right)}}{\sqrt{n}\left((K+s) \frac{F\left(t_{j}\right)}{G\left(t_{j}\right) / D_{\text {ref }}}+K \frac{1-F\left(t_{j}\right)}{G\left(t_{j}\right) / D_{\text {ref }}}\right)}
$$

$$
\begin{aligned}
& =1 / \sqrt{n}\left[\frac{K_{s}+1}{K_{s}+F\left(t_{j}\right)} \sqrt{\frac{G\left(t_{j}\right)}{D_{\text {ref }}}-F\left(t_{j}\right)} \sqrt{F\left(t_{j}\right)}\right] \\
& =1 / \sqrt{n}\left[\frac{1}{1-\frac{1-F\left(t_{j}\right)}{K_{s}+1}} \sqrt{\frac{G\left(t_{j}\right)}{D_{\text {ref }}}-F\left(t_{j}\right)} \sqrt{F\left(t_{j}\right)}\right]
\end{aligned}
$$

\footnotetext{
${ }^{31}$ Independence between asset failures is assumed. Cases for positive or negative correlation are both imaginable and would lead to an additional covariance term, which could also be positive or negative. As these effects are second order, they are of minor interest in the analysis.

${ }^{32}$ For example, extra maintenance costs for emergency teams, provisional solutions, and so forth.
} 
Clearly, the coefficient of variation decreases with $n$ in line with the law of large numbers. Thus, an issue of implicit discrimination might arise if regulation authorities do not account for additional costs due to this idiosyncratic risk. A second question arises: Does the regulator reinforce or weaken this effect by introducing quality regulation mechanisms? Unfortunately, the analytical model does not provide a clear answer. Both expected costs and the standard deviation increase in $s$; thus, the impact on $\operatorname{VarC}$ is ambiguous.

\section{EMPIRICAL ANALYSIS: STRUCTURAL ASSUMPTIONS, FAILURE BEHAVIOR AND COST DATA}

In order to evaluate the risks linked to the network size of real world network operators, the Monte Carlo simulation technique is applied in Matlab. Thereby, different asset classes are distinguished and a typical network configuration is assumed. The stochasticity of the model is generated via asset group and age dependent random failure events, which lead to probability distributions for quality indices and a total cost $C+S$. Three sources of uncertainty are included in the model. First, asset failure may or may not occur for any single asset in the network. Second, asset failures may lead to outages if assets are not redundant, meaning that another network component may take on the function of the failed equipment. A binomial distribution based on redundancy assumptions generates random outages based on failures and links the outages to the number of customers that would be affected. Third, the duration of outages varies significantly. Failure times for each outage are considered via a skewed Weibull distribution.

\section{i. Network Components and Structure}

The simulation approach assumes a network consisting of single assets linked in a network structure. An illustration of the basic network structure of a German operator is presented in Figure 1. Different network sizes will be accounted for using a size parameter, which will be handled as a multiplier building on network length for the basic structure. Network length is one of the central cost drivers and is therefore taken by the German regulator BNetzA, for example, as a proxy for size in efficiency comparisons. ${ }^{33}$ The choice of network length as the size multiplier also draws on the fact that the representative network structure of the average operator is built on the basis of a sample of German operators of all sizes. We therefore choose network length as the scaling parameter. All failures are considered to be independent of each other, i.e., the failure of one component has no technical impact on the state of any other component.

Nevertheless, if a component at a higher voltage level fails (such as a transformer), all customers connected to that component will naturally be affected. The number of customers affected by a component failure depends primarily on two aspects: the number of connected customers and redundancy. The number of connected customers is linearly distributed across the number of components. Failure consequences are attenuated with the use of redundancy concepts. If one component fails, redundancy may prevent failures because another component compensates for the failed component. In general, the components' age structure follows the lifetime distribution $H\left(t, t_{j}\right)$ that occurs in the stationary state.

\footnotetext{
${ }^{33}$ See ARegV (2012).
} 


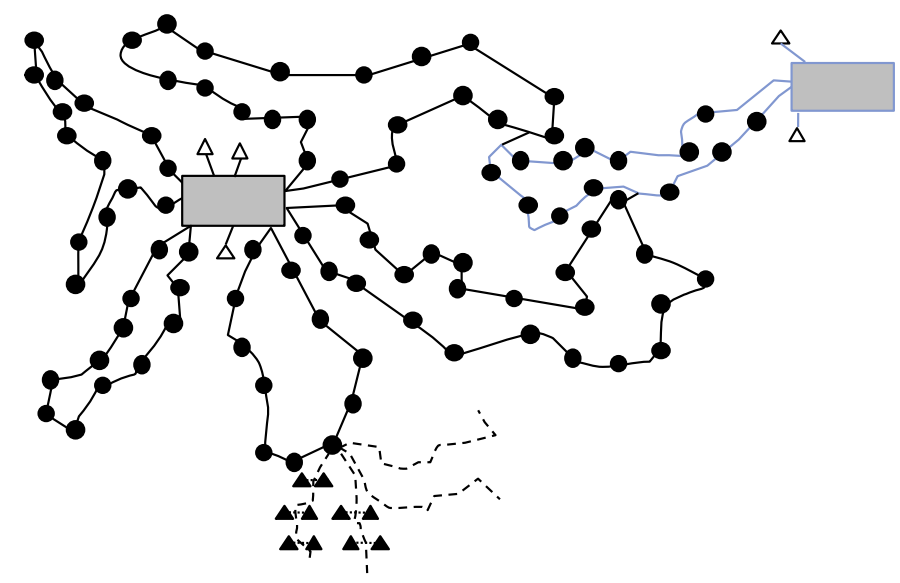

\begin{tabular}{cll}
\hline Sign & Equipment & Quantites \\
\hline$\square$ & Transformer & 12 \\
$\square$ & Circuit breaker & 90 \\
- & Overhead lines (mv) & $450 \mathrm{~km}$ \\
- & Cables (mv) & $150 \mathrm{~km}$ \\
- & Relay stations & 600 \\
--- & Overhead lines (Iv) & $1,200 \mathrm{~km}$ \\
--- & Cables (Iv) & $200 \mathrm{~km}$ \\
$\Delta$ & Industry customers & 15 \\
$\Delta$ & Comm. customers & 4,200 \\
$\Delta$ & Households & 57,400 \\
\hline
\end{tabular}

Figure 1: Basic network structure (for details see Appendix IV)

\section{ii. Failure Rates}

The failure rates of components technically depend on a multitude of different factors, such as age, electrical stress (for instance overload) and mechanical stress (wear and tear, e.g., through tension, pressure, and vibrations). In the context of network simulations, many approaches only capture the influence of age as complete data sets for all other influencing factors are rarely available and the age of a network is intimately linked to investment strategies. For the present simulation model, age-dependent failure rate curves are derived from two major distribution parameters and approximated using Weibull distributions. ${ }^{34}$

\section{iii. Failure Duration/Downtimes}

Failure durations or downtimes indicate the time span during which customers are not supplied with power; they consequently have a significant impact on quality indices. Average failure durations linked to asset clusters are available in outage statistics such as, for instance, VDN (2005, pp. $28 \mathrm{ff}$.). As this paper focuses only on average durations, distribution laws are estimated based on confidential project data available to the authors and adapted in order to match the average failure durations from the published source. The use of a Weibull distribution is an appropriate approach to modeling failure durations due to its skewness. ${ }^{35} \mathrm{In}$ practice, the majority of outages are relatively short, while a few outages may last a very long time.

\section{iv. Penalties, Replacement Costs and Network Tariffs}

Estimates for replacement costs $K$ are based on Consentec et al. (2008, pp. $113 \mathrm{ff}$.). Penalties $s$ are calculated for each asset class and consider the number of customers affected, the degree of redundancy, the average duration of an outage, the average consumption of each customer segment and a standard penalty of $€ 10$ per $\mathrm{kWh}$ of energy not supplied. ${ }^{36}$ One further assumption is that premature replacement leads to additional costs of $20 \%$ compared to planned replacements due, for instance, to add-on-expenses for provisional solutions.

\section{v. Structure of German Electricity Distribution}

Research articles, regulatory authority publications and similar documents detailing the size and the structure of German network operators have not been published to date.

\footnotetext{
${ }^{34}$ See Appendix V.

${ }^{35}$ Data from VDN (2005, pp. 66 ff.) show that failure duration distributions are skewed, caused by a small number of very long outages.

${ }^{36}$ This assumption is made based on Billington (2000) and Roberts (2001). This assumption will be modified to $€ 1 / \mathrm{kWh}, € 50 / \mathrm{kWh}$ and $€ 100 / \mathrm{kWh}$.
} 
Consequently, a survey was conducted gathering relevant data on cable and overhead length, transmitted energy, points of consumption and supplied inhabitants from all 880 German network operators, of which only 700 data sets could be extracted due to insufficient compliance with legal obligations. These data, describing network structures in 2008, were gathered from the network operators' websites. ${ }^{37}$ In order to structure the data sets, network operators were sorted by total network length. The overall range is from $106.000 \mathrm{~km}$ (EnBW Regional) to $30 \mathrm{~km}$ (several very small local operators). Five percent quantiles regarding network length were built, each containing 35 network operators. Consequently, the $0-5 \%$ quantile includes the 35 largest network operators. Figure 2 shows the repartition of structural indices by quantiles.

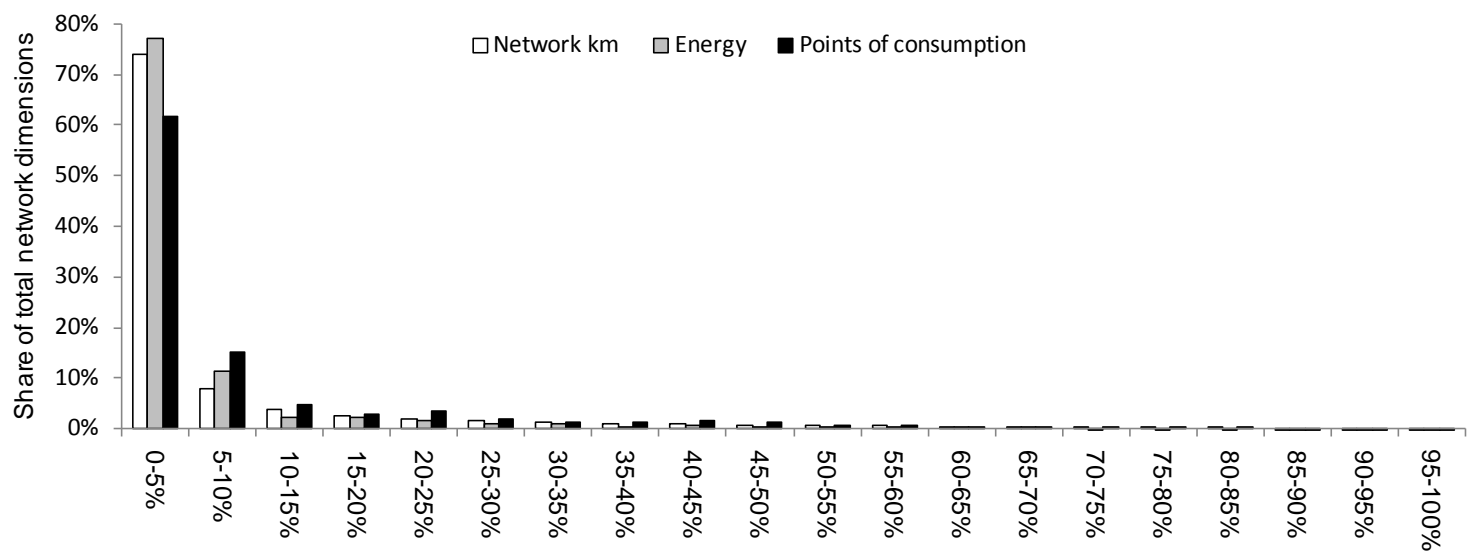

Quantile of network operators sorted by size (35 firms are grouped in one quantile)

Figure 2: Share of network operations by size in quantiles

An initial, very clear result is the extremely high concentration of network activity within the big operators. The 35 largest companies operate approximately $70 \%$ of the total network in terms of length, provide $80 \%$ of all energy through their networks, and cover $60 \%$ of the consumption points. From all the data and figures presented, one can conclude a very high degree of concentration. The typical firm described before, located in the 10-15\% quantile, operates a network with a length of $2,000 \mathrm{~km}$ and 70,500 points of consumption, transmitting $1,715 \mathrm{GWh}$. However, $80 \%$ of all companies operate a network of less than 1,000 km. The median network operator has a network size of only $370 \mathrm{~km}$. This will be of significant impact in the simulation, as we expect large network operators to be less affected by single network events and consequently less risky.

\section{SIMULATION AND SiMULATION RESULTS}

In the following section, the results from the Monte Carlo simulations are presented in order to discuss the propositions made in section 2 in further detail. The replacement strategy considered implements an age-based replacement rule based on the stationary calculus described above.

Also, in this context, the assumption of representative network structures leads to a conservative estimation of potential discrimination. Idiosyncratic risk stemming from network operation is measured by the coefficient of variation $\sigma / \mu$, abbreviated to $\operatorname{VarC}$ in tables and illustrations. In the first step, the absolute failure numbers are simulated in $n=100,000$ runs following the binomial law with respect to redundancy assumptions. Total expenses for premature replacement and quality penalties add up to approximately $€ 9 \mathrm{~m}$ (given a size of 1 ), which is significant in view of a total turnover based on network tariffs of approximately €38 $\mathrm{m}$ and thus is close to approximately $25 \%$ of turnover. ${ }^{38}$ Total network quality as measured by

\footnotetext{
${ }^{37}$ This is possible due to the fact that German distribution network operators are obliged to publish a significant amount of structural data in line with legal obligations. See $\S 27$ Stromnetzentgeltverordnung (StromNEV, 2006).

38 These revenues were estimated based on the average transmitted energy in our data samples. Tariffs are based on BNetzA (2008, pp. 45). LV-tariffs were calculated as the average of Dc and lb tariffs, the MV-tariff was calculated as the average of lg values, and only data from 2008 were considered. One has to take into account
} 
the System Average Interruption Duration Index (SAIDI) is approximately 30 minutes per year. ${ }^{39}$ This value appears low, as European countries such as Italy or Greece report SAIDIs of more than 100 minutes, but is very plausible for Germany and other countries such as the Netherlands or Austria.

Three major assumptions are relevant in explaining this low SAIDI level. First, the asset lifetime distribution following the stationary state optimum has an impact on the SAIDI. Networks with a higher number of older components will see higher SAIDI values. Second, an optimal replacement strategy that considers additional costs due to penalties and premature replacement is assumed, which is not yet found in many European countries. Third, average interruption durations are based on German data and may vary in other countries. If these assumptions were modified, SAIDI would increase significantly. Interestingly, quality penalties only account for $3 \%$ of replacement-related expenses under the given assumption of $10 € / \mathrm{kWh}$.

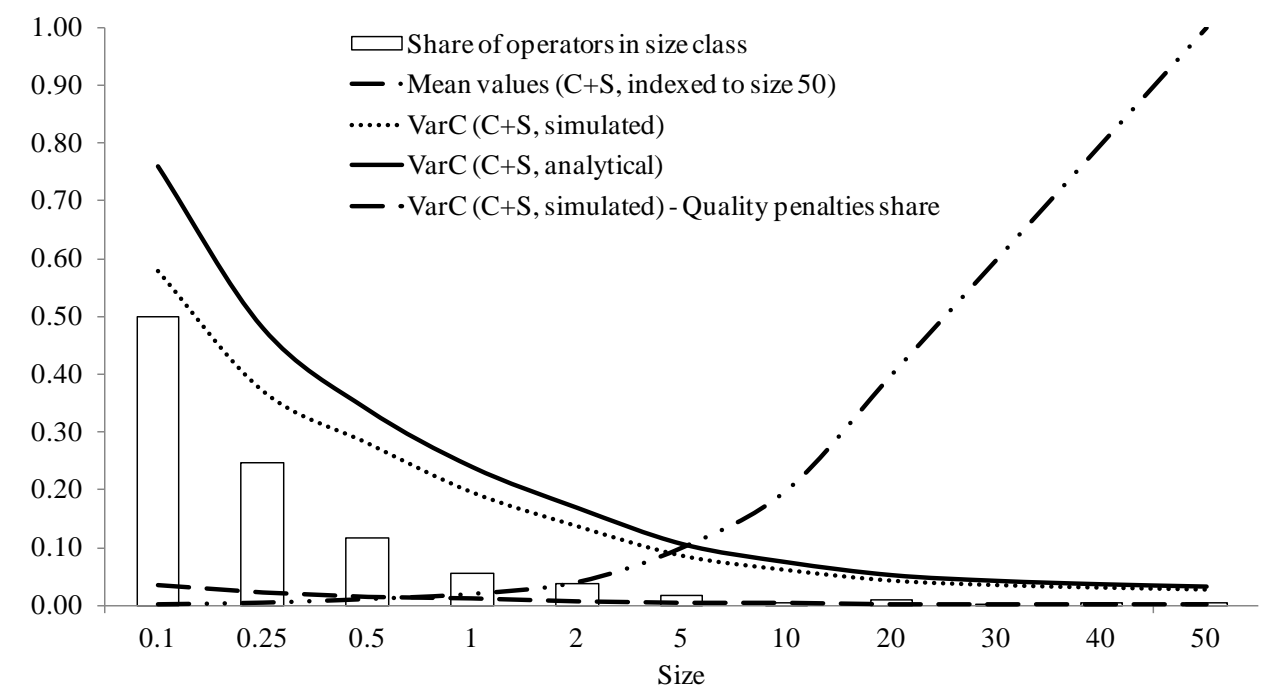

Figure 3: Effect of network size

Figure 3 shows the idiosyncratic risk and the share of German distribution network operators that are of the given size. As discussed in Propositions 1 and 2, total costs increase proportionally, standard deviation increases under-proportionally and thus specific risk, measured by the coefficient of variation, decreases with network size. The discriminatory effect is considerable as the coefficient of variation of a network operator of approximately $100,000 \mathrm{~km}$ corresponds to approximately 0.03 , the values of a small operator (with $200 \mathrm{~km}$ ) being 22 times higher. Interestingly from the standpoint of a regulation authority, $95 \%$ of network operators will be subject to a coefficient of variation greater than 0.15 , whereas the $5 \%$ of largest network operators will be affected by an average coefficient of variation of 0.06. The coefficient of variation for the standard network operator of size one amounts to 0.2. The observed effect supports the relationship formulated by the analytical model. It is moderately greater than the relationship of $1 / \sqrt{n}$ derived in the analytical model, which is due to some changes in the assumptions regarding stochastic properties in relation to redundancy and failure durations and the use of a Weibull failure distribution. Overall, however, the analytical model proves a valid instrument to approximate simulation results. KolmogoroffSmirnov tests show that variations in total costs and SAIDI follow a normal distribution starting at a size of 30 , corresponding to a $60,000 \mathrm{~km}$ network, while the System Average Interruption Frequency Index (SAIFI) is already normally distributed around the size of $20 .{ }^{40}$

that only $50 \%$ of total network costs are considered open to influence by the German regulatory authority due to the influences of transmission networks, license fees and subventions for renewable energy sources.

${ }^{39}$ The SAIDI is the average outage duration for each customer served per year. It is calculated by dividing the sum of all customer interruption durations by the total number of customers served.

${ }^{40}$ The SAIFI is calculated analogously to the SAIDI. It is calculated by dividing the sum of all customer interruption frequencies by the total number of customers served. 
The focus of the discussion will be on quality penalties as regulators have considerable discretion regarding their level. Higher penalties will lead to earlier replacement, whereas financial risk may increase with lower penalties due to higher penalty expenses. Quality penalties, if set at the adequate level of customers' valuation, seem to be an effective instrument to incentivize a socially optimal quality standard. Table 1 shows the results for the expected values $\mu$ of the direct quality measure SAIDI and total cost $C+S$, standard

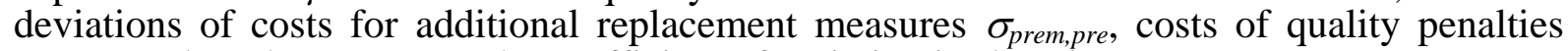
$\sigma_{\text {prem,s }}$ and total costs $\sigma_{C+S}$. The coefficient of variation is also given.

\begin{tabular}{lllllll}
\hline Penalty & $\boldsymbol{\mu}_{\text {SAIDI }}$ & $\boldsymbol{\mu}_{\mathrm{C}+\boldsymbol{S}}$ & $\sigma_{\mathrm{C}+\boldsymbol{S}}$ & $\sigma_{\text {prem,pre }}$ & $\sigma_{\text {prem,s }}$ & $\sigma_{\mathrm{C}+\boldsymbol{S}} / \boldsymbol{\mu}_{\mathrm{C}+\boldsymbol{S}}$ \\
\hline \hline $\boldsymbol{€ 1 / k W h}$ & 51 & 13,756 & 2,789 & 2,786 & 5 & 0.203 \\
$\mathbf{€ 1 0 / k W h}$ & 30 & 14,067 & 2,744 & 2,716 & 45 & 0.195 \\
$\mathbf{€ 5 0 / k W h}$ & 13 & 14,879 & 2,715 & 2,586 & 174 & 0.182 \\
$\mathbf{€ 1 0 0 / k W h}$ & 10 & 15,562 & 2,681 & 2,422 & 319 & 0.172 \\
\hline
\end{tabular}

Table 1: Effect of quality penalties

An increase in quality penalties leads to a reduction in the risk measure VarC. The range of the SAIDI levels from approximately 50 to 10 minutes shows that quality regulation can have a major impact on network quality. In the case of Germany, socially optimal quality penalties of approximately $€ 10 / \mathrm{kWh}$ would lead to slightly higher SAIDIs than today, with a switch from about 20 minutes currently, to 30 minutes. Intuitively, expected total cost increases with higher penalties while the overall effect on the standard deviation decreases: The trade-off between the price effect (higher cost for each failure) and the quantity effect (fewer failures due to earlier replacements) is visible, as $\sigma_{p r e m, s}$ (the standard deviation exclusive of penalties) increases less than $\sigma_{\text {prem,pre }}$ (the standard deviation from additional cost due to premature replacements, no penalties included) decreases.

This is an aspect that should be of interest to the regulator: Increasing quality penalties will reduce the firm's risk exposure (although it increases total costs of course).

\section{THE IMPACT OF IDIOSYNCRATIC RisK ON THE COST OF CAPITAL}

Based on the previous section, this section provides an empirical assessment of the financial consequences for regulated firms. Required capital cost markups are calculated for German electricity network operators and compared to current actual capital costs. The German regulator simply limits capital cost to a uniform rate, $7.38 \%$, for all operators irrespective of firm specifics. Equity cost is calculated by the CAPM. The WACC is calculated by taking the firm's cost of debt and averaging this using an equity-debt ratio of $2: 3{ }^{41}$ In the framework of the financial model introduced in section 2 , the return on the capital used is given by equation (2):

$$
r=\frac{Y_{i}-Y_{o}-M_{0}}{A+B} .
$$

In the rate setting process, the regulator should then allow for the expenses of liquidity management $M_{0}$ and include the buffer $B$ in the capital base. However, it may be difficult to apply this approach due to a lack of reliable data. Thus, the regulator may alternatively increase the allowed return on the regulated asset base $A$. The required modification is given by

$$
r=\frac{Y_{i}-Y_{o}}{A}-\frac{M}{A}
$$

where $M / A$ describes the costs related to liquidity management as a fraction of the regulated asset base. At the same time $M / A$ is the markup on conventional capital costs required by the

\footnotetext{
${ }^{41}$ See Frontier Economics (2008) and $\S 7$ Abs. 6 in the German regulation of electricity charges (StromNEV 2011). Debt is further capped at a “common market rate,” cf. § 5 Abs. 2 (StromNEV 2011).
} 
operators. Subsequently, this intuitive interpretation is used to compute necessary increases in the rate of return to compensate for the respective exposures to firm-specific risk.

As the failure behavior of assets leads to a distribution with fat tails in the chosen empirical context, the assumption of normally distributed cash flows is dropped. Instead, the optimal financial policy here is found by simulating $n=100,000$ cash flow realizations and subsequently choosing optimal capital buffers $B$ and credit line commitments $L$ to minimize liquidity costs. We therefore minimize losses following the adaption of equation (9) to the case of discretely simulated overall cash flows with equal probability $1 / N$.

$$
\begin{aligned}
& \max _{B, L}[-M(B, L, x)] \\
& =\max _{B, L} \sum_{i=1}^{N} \frac{1}{N}\left(1_{x_{i}<-L}[(x+L)(r+u)]+1_{x_{i} \geq-L \wedge x_{i}<-B}\left[(x+B)\left(r+s_{2}\right)\right]\right)+(B-L) s_{1}-B r
\end{aligned}
$$

We use capital cost data based on German regulation, with a WACC of $7.38 \%{ }^{42}$ The costs of pure network operation (stochastic failure and corresponding cash flow patterns obtained in the preceding section) are supplemented by the remaining costs of the operator, which are assumed to be independently and normally distributed. These other costs are obtained top down by subtracting EBT and network operation cash flows from yearly revenues. Thus, by definition, this residual also incorporates all other sources of uncertainty, e.g., cost, demand, or revenue uncertainty.

Different scenarios are investigated to highlight the impact of regulatory settings and firm characteristics on the required markup. First, two standard deviation scenarios (5\% SD and $10 \%$ SD) are defined, with $5 \%$ and $10 \%$ of expected other costs respectively. Second, the firm may choose to pay either $0 \%$ or $50 \%$ of its profits (EBT) to shareholders (dividend payment: $0 \% \mathrm{DP}$ and $50 \% \mathrm{DP}$ ). The usual assumption in this context would be that firms realize profits first and then decide how much to distribute. However, for some private companies and especially in the context of small public enterprises, it is not uncommon to guarantee a minimum payout on expected profits to investors. In the case of public firms, one could also think of pre-engaged income for other cross-subsidized municipal activity, such as the maintenance of infrastructure or schools. In addition, three different cost specifications were distinguished; the difference in results was however minor. ${ }^{43}$

The resulting markups regarding the different scenarios are shown in Figure 4. The current actual WACC of $7.38 \%$ granted by the German regulator BNetzA is depicted as a baseline. The variation of markups between network operators of different size is very important. The smallest network operators would need additional idiosyncratic risk premia of between $2-3 \%$. This corresponds to the money not available to network operators. Total capital cost in such a case would have to amount to approximately $9.4 \%$ or $10.1 \%$ to compensate for the liquidity management costs associated with idiosyncratic size risk.

\footnotetext{
${ }^{42}$ For the quantification of financial effects, the WACC is taken as $7.38 \%$, which may be considered conservative in comparison to current international regulatory settings for returns on capital. This is based on the return rate for equity of $9.29 \%$ set by the German regulator and an interest rate on debt of $6.1 \%$, given a $40 \%$ share of equity in total capital. For the standard network operator, approximate revenues of $€ 38 \mathrm{~m}$ and a firm value of approximately $€ 160 \mathrm{~m}$ are derived as an approximation from network charges and average customer sizes (see footnote 38). Correspondingly, earnings before interest and taxes (EBT) have to be close to $€ 6 \mathrm{~m}$ or $15.65 \%$ of total revenues in order to cover capital costs.

${ }^{43}$ A low, medium, and high cost scenario were defined. Whereas the weighted capital cost rate is set at $7.38 \%$ throughout, in the low-cost scenario, the fixed credit line fee is $0.25 \%$, the rate for actual usage is an additional $2 \%$, and short-run capital provision is assured at $12.5 \%$. The parameters for the medium-cost scenario are $0.5 \%, 3 \%$ and $12.5 \%$. The high-cost scenario then assumes a substantially higher rate of 35\% for short-run capital provision as may occur when asset fire sales become necessary. Interestingly, throughout the different cost scenarios there is only a slight variation of approximately $10 \%$ upwards and downwards respectively. Therefore, we employ the medium-cost scenario in the following exposition of results.
} 


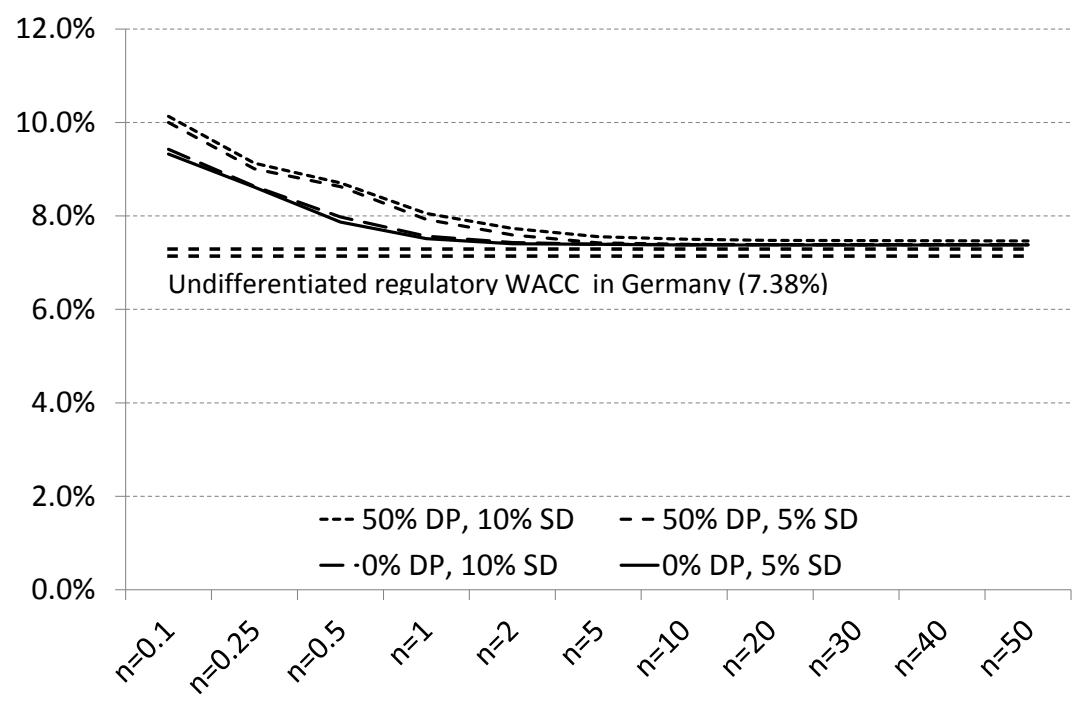

Figure 4: Impact of size variation on capital cost markups

For smaller network operators, a higher standard deviation again has a less sizeable impact than the imposition of minimum dividend payments. This is somewhat different for larger operators: The markups are near zero for all DP-SD scenarios except for the extreme $50 \%$ DP/10\% SD scenario. Only the combination of both effects will lead to a noticeable, but still small-scale, increase in liquidity management costs. This result is due to the different scaling of the standard deviations related to asset failures and other costs. Whereas the law of large numbers is applied to asset failures, the standard deviation from other costs by definition persists even for very large operators. This may originate from demand fluctuations or input price fluctuations. We further tested the impact of quality penalties on the reported markups on the cost of capital, but found an increase or decrease in the markup of $10 \%$ at best. Consequently, the level of quality penalties does not contribute in any important way to discrimination.

\section{SUMMARY AND CONCLUSION}

In this article, the impact of firm-specific risk borne by network operators in relation to capital costs has been discussed. By applying equity prices to cost bases determined from physical or accounting data, regulators typically ignore costs related to firm-specific risk. In a stylized model environment, including corporate liquidity management, we have identified the source of this disregard and laid out the consequences: negligence of justifiable cost elements gives rise to discrimination issues. Difficulties in refinancing ongoing business activities may also arise. When a regulator is concerned with granting a level of remuneration allowing firms to stay in business, it should thus consider idiosyncratic risk sources. Here the article makes an important contribution by deriving possible required markups consistently from a formal model of liquidity management and idiosyncratic risk. Hence, an overall framework is provided, combining operational and financial modeling in view of optimal regulatory rate setting.

The firm-specific risk considered here is the cash flow risk related to component failures. The relative importance of this risk is dependent on firm size as a consequence of the law of large numbers. Especially after the introduction of incentive regulation, smaller firms typically complain of increased burdens stemming from the high volatility of their reinvestment needs. Here, stochastic failures imply a type of economies of scale which has scarcely been addressed in the literature. These failures induce a higher need for (financial) capital. This tends to be neglected by most regulators, which apply a return rate to the regulatory asset base, solely considering systematic risk. Network operators thus suffer from substantial financial costs due to firm-specific risks related to their size, which is shown analytically and empirically: The additional capital costs correspond to total rate markups ranging between $0 \%$ and approximately $2.9 \%$, which corresponds to up to $40 \%$ of capital costs for the smallest operators. These estimates are comparable to the effects derived in Evans and Guthrie (2005). However, for the average network operator with approximately 2,000 km of network, the 
impact of idiosyncratic risk is found to be moderate. The estimates are conservative assessments based only on the cost of liquidity management. Other issues, e.g., risk aversion on the part of the firm's management, may even aggravate the effects described.

Beyond the size effects considered here, other sources of idiosyncratic risk, such as heterogeneous asset age, may induce similar consequences for capital costs. These should be included in the regulatory process as long as they alter financing needs. Typically, as idiosyncratic risks stem from individual sources, they are mutually independent and financing needs will increase. However, only the study of more elaborated models of the joint distribution of idiosyncratic risks in question may provide deeper insights, depending on the specific case inspected. This is left to further research.

A more in-depth discussion of regulatory responses to this potential discrimination is beyond the scope of the present paper. Nevertheless, it should be mentioned that choosing the correct compensation level is important to avoid creating perverse incentives. In the same way that neglecting size-related capital cost markups will bias the choice of operating scale towards larger firm sizes, overcompensation has a tendency to reduce firm sizes. The difference is that in the former case, firms might not break even, which risks additional welfare losses caused by insolvency, bankruptcy, or inefficient takeovers. This, of course, also holds for incorrect compensation for other idiosyncratic risks. 


\section{Appendix I}

\section{APPENDIX}

The optimal simultaneous choice of up-front capital provision $B$ and choice of credit lines $L$ is implicitly defined by solving the firm's objective function contained in equation (9). Usually, $s_{1}<<s_{2}$, which does not restrict the following results:

$$
\max _{B, L}\left[\int_{-\infty}^{-L}[(x+L)(r+u)] f(x) d x+(B-L) s_{1}+\int_{-L}^{-B}\left[(x+B)\left(r+s_{2}\right)\right] f(x) d x-B r\right]
$$

Optimization with respect to $L$ and $B$ gives the following results:

$$
\begin{aligned}
& \frac{\partial E}{\partial L}=\frac{\partial\left(\int_{-\infty}^{-L}[(x+L)(r+u)] f(x) d x+(B-L) s_{1}+\int_{-L}^{-B}\left[(x+B)\left(r+s_{2}\right)\right] f(x) d x-B r\right)}{\partial L} \\
& =-s_{1}+(r+u)(F(-L)-L f(-L))+\left(r+s_{2}\right) B f(-L)+\left(u-s_{2}\right) \frac{\partial \int_{-\infty}^{-L} x f(x) d x}{\partial L}
\end{aligned}
$$

Assuming normal distribution characteristics for stochastic cash flows $x$, an implicit solution of the optimization is possible:

$$
\begin{aligned}
& =-s_{1}+(r+u)(F(-L)-L f(-L))+\left(r+s_{2}\right) B f(-L)+\left(u-s_{2}\right) \frac{\partial\left(\mu F(-L)-\sigma^{2} f(-L)\right)}{\partial L} \\
& =-s_{1}+(r+u)(F(-L)-L f(-L))+\left(r+s_{2}\right) B f(-L)+\left(u-s_{2}\right)\left(\mu F(-L)-\sigma^{2} f^{\prime}(-L)\right) \\
& f^{\prime}(-L)=\left(-\frac{-L-\mu}{\sigma^{2}}\right) f(-L) \\
& \Leftrightarrow \sigma^{2} f^{\prime}(-L)=(L+\mu) f(-L) \\
& \Leftrightarrow-L f(-L)=\mu f(-L)-\sigma^{2} f^{\prime}(-L) \\
& \quad=\quad-s_{1}+(r+u) F(-L)-(r+u) L f(-L)+\left(r+s_{2}\right) B f(-L)+\left(u-s_{2}\right) L f(-L) \\
& =-S_{1}+(r+u) F(-L)-(r+u) B f(-L)-\left(r+s_{2}\right) L f(-L) \\
& \frac{\partial E}{\partial L}=0
\end{aligned}
$$

Algebraic transformation leads to $L=B+\frac{(r+u) F(-L)-s_{1}}{\left(r+s_{2}\right) f(-L)}$.

The solution for $B$ is of course analogous:

$$
\begin{aligned}
& \frac{\partial E}{\partial B}=\frac{\partial\left(\int_{-\infty}^{-L}[(x+L)(r+u)] f(x) d x+(B-L) s_{1}+\int_{-L}^{-B}\left[(x+B)\left(r+s_{2}\right)\right] f(x) d x-B r\right)}{\partial B} \\
& =s_{1}-r+\left(r+s_{2}\right) \frac{\partial \int_{-\infty}^{-B} x f(x) d x}{\partial B}+\left(r+s_{2}\right)(F(-B)-B f(-B)-F(-L))
\end{aligned}
$$

Again, assuming normally distributed cash flows will make the following solution possible:

$$
=\left(r+s_{2}\right)(F(-B)-F(-L))+s_{1}-r .
$$

$\frac{\partial E}{\partial B}=0:$ Algebraic transformation leads to:

$$
F(-B)=F(-L)+\frac{r-s_{1}}{r+s_{2}} .
$$




\section{Appendix II}

$$
\begin{aligned}
& K\left(1-F\left(t_{1}\right)\right)=s f\left(t_{1}\right) G\left(t_{1}\right)-F\left(t_{1}\right)\left(1-F\left(t_{1}\right)\right) \\
& \Leftrightarrow K_{s}=\frac{f\left(t_{1}\right) G\left(t_{1}\right)-F\left(t_{1}\right)\left(1-F\left(t_{1}\right)\right)}{\left(1-F\left(t_{1}\right)\right)} \\
& \Leftrightarrow K_{s}=\frac{m\left[t_{1}-\frac{1}{2} m\left(t_{1}-t_{a}\right)^{2}\right]-m\left(t_{1}-t_{a}\right)\left(1-m\left(t_{1}-t_{a}\right)\right)}{\left(1-m\left(t_{1}-t_{a}\right)\right)} \\
& \Leftrightarrow\left(\frac{1}{2} m\right) t_{1}^{2}+\left(K_{s}-m t_{a}\right) t_{1}+\left(\frac{1}{2} m t_{a}^{2}+t_{a}-\frac{K_{s}}{m}-K_{s} t_{a}\right)=0
\end{aligned}
$$

Solving this quadratic equation gives:

$$
t_{1_{1} / 1_{2}}^{*}=t_{a}-\frac{K_{s}}{m} \pm \frac{\sqrt{K_{s}{ }^{2}+2 K_{s}-2 m t_{a}}}{m} \Rightarrow t_{1_{1} / 1_{2}}^{*}=t_{a}+\frac{\sqrt{K_{s}{ }^{2}+2 K_{s}-2 m t_{a}}-K_{s}}{m} .
$$

\section{Appendix III}

It is sufficient to show that total cost is convex in replacement age:

$$
\begin{aligned}
& \mu=n\left((K+s) \frac{m\left(t_{j}-t_{a}\right)}{t_{j}-\frac{m}{2}\left(t_{j}-t_{a}\right)^{2}}+K \frac{1-m\left(t_{j}-t_{a}\right)}{t_{j}-\frac{m}{2}\left(t_{j}-t_{a}\right)^{2}}\right) \\
& =n\left(s \frac{m\left(t_{j}-t_{a}\right)}{t_{j}-\frac{m}{2}\left(t_{j}-t_{a}\right)^{2}}+K \frac{1}{t_{j}-\frac{m}{2}\left(t_{j}-t_{a}\right)^{2}}\right)
\end{aligned}
$$

This is done by showing that the second derivative of this composition of polynomials is positive:

$$
\begin{aligned}
& \frac{\partial \mu}{\partial t_{j}}=n\left(s \frac{m\left(t_{j}-\frac{m}{2}\left(t_{j}-t_{a}\right)^{2}\right)-m\left(t_{j}-t_{a}\right)\left(1-m\left(t_{j}-t_{a}\right)\right)}{\left(t_{j}-\frac{m}{2}\left(t_{j}-t_{a}\right)^{2}\right)^{2}}+K \frac{-\left(1-m\left(t_{j}-t_{a}\right)\right)}{\left(t_{j}-\frac{m}{2}\left(t_{j}-t_{a}\right)^{2}\right)^{2}}\right) \\
& \frac{\partial^{2} \mu}{\partial t_{j}{ }^{2}}=n\left(s m \frac{t_{a}+\frac{m}{2}\left(t_{j}-t_{a}\right)^{2}}{\left(t_{j}-\frac{m}{2}\left(t_{j}-t_{a}\right)^{2}\right)^{2}}+K \frac{m\left(t_{j}-t_{a}\right)-1}{\left(t_{j}-\frac{m}{2}\left(t_{j}-t_{a}\right)^{2}\right)^{2}}\right) \cdot \\
& =n(\underbrace{s m \underbrace{m\left(t_{j}-t_{a}\right)\left(t_{j}-\frac{m}{2}\left(t_{j}-t_{a}\right)^{2}\right)-2\left(t_{a}+\frac{m}{2}\left(t_{j}-t_{a}\right)^{2}\right) \underbrace{\left(1-m\left(t_{j}-t_{a}\right)\right.}_{<})}_{>0}}_{>0}) .
\end{aligned}
$$

By inspecting the following transformation, this can easily be seen. $\mu$ is convex in $t_{j}$. 


\section{Appendix IV}

This network structure is based on Obergünner (2005), who presents the components of a standard distribution network operator in German electricity distribution. The network components (or asset clusters) are as follows: transformers, circuit breakers, overhead lines (medium and low voltage), cables (medium and low voltage), relay stations. This structure consists of: six transformer stations (with 12 transformers and 90 circuit breakers), 600 relay stations, and 2,000 km of cables and overhead lines.

Transformer stations (with the transformers and circuit breakers), which are connected to the high voltage grid, transform electricity to medium voltage and feed into medium voltage rings. Industry customers are directly connected to transformer stations. Based on the analytical network modeling approach in Consentec et al. (2008), which has also been used by the German regulator for various regulatory purposes, we determine that five medium voltage rings, each $20 \mathrm{~km}$ in length, are connected to each transformer station. A medium voltage ring consists of cables and overhead lines, which connect several relay stations per ring. At each relay station, electricity is transformed to low voltage and fed into low voltage cables and overhead lines which provide low voltage customers via a string structure. Each ring includes 20 relay stations, from which four low voltage lines per relay station (each $600 \mathrm{~m}$ in length) connect households, commercial customers and others (i.e., traffic, agriculture, public institutions). This corresponds to a typical distribution network operator’s structure.

\section{Appendix V}

The $80 \%$ survival age indicates the age that $80 \%$ of assets will attain without replacement or major repair (the value of the cumulative distribution function CDF attaining 0.2), the 20\% survival age indicates the age at which $80 \%$ of assets in one cluster will have failed $(\mathrm{CDF}=0.8)$. The estimates for these survival ages reflect practitioners' current expectations of asset lifetimes. ${ }^{44}$ Based on these assumptions, Weibull failure distribution laws for the conditional failure rate have been estimated (see Figure 5 for cumulated distribution functions).

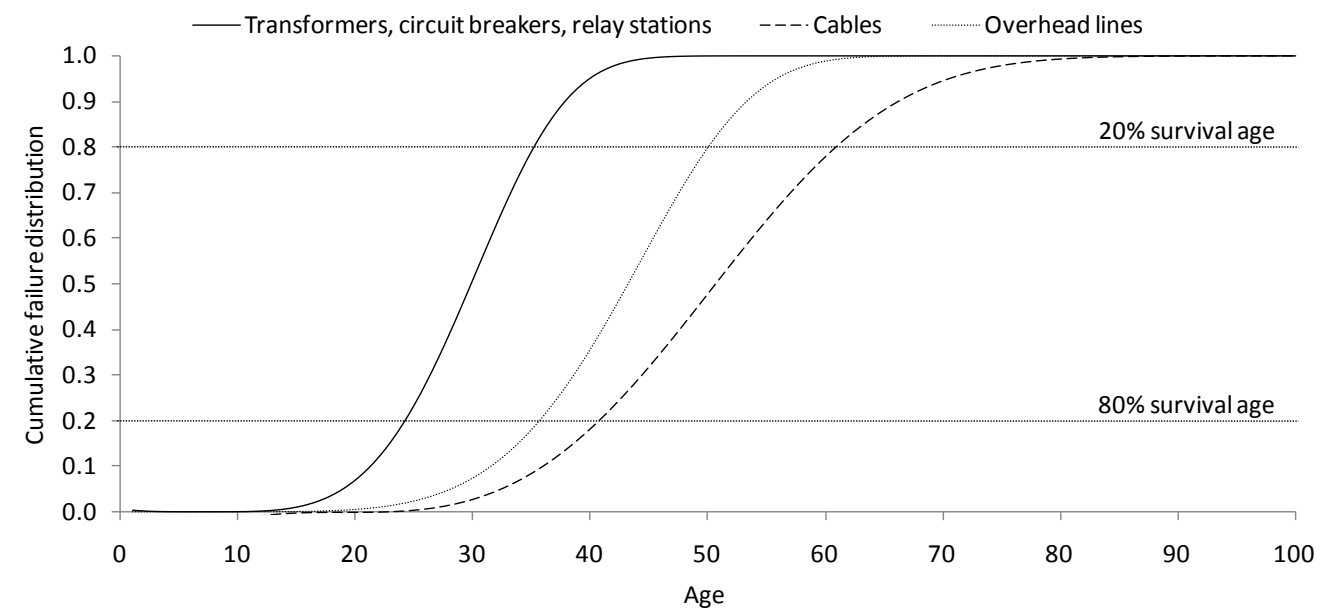

Figure 5: Cumulative failure distribution based on Weibull law

\section{Appendix VI}

The customer segment definitions were taken from BNetzA (2008, p. 45), drawing on the overall yearly consumptions from BDEW (2008). The number of customers was derived from

\footnotetext{
${ }^{44}$ A vast body of empirical research concerning the lifetime of network components has been published to date. One research article regarding cables is Densley (2001). Lindquist et al. (2008) analyze the reliability of circuit breakers. FGH (2006) presents aging models for all sorts of different component types. Unfortunately, there is no single article that summarizes research in this field and is able to provide consistent lifetime distributions for all asset types required in the simulation. A first obstacle is the vast number of possible different definitions of survival age and approach to modeling it. Second, research focuses mostly on transformers, circuit breakers, and cables. To our knowledge, there is no extensive research available on relay stations. Consequently, the cumulative failure distributions are derived as assumptions from practical insights.
} 
the data gathered with reference to the share of total line length $(2,000 \mathrm{~km}$ compared to approximately 1,600,000 km overall in Germany).

\begin{tabular}{lllll}
\hline Equipment & Unit & Industry & Households & Commercial/others \\
\hline \hline Total yearly consumption & MWh & $256,000,000$ & $139,500,000$ & $146,700,000$ \\
Yearly consumption/customer & MWh & 24,000 & 3.5 & 50 \\
Number for operator size 1 & $\#$ & 12 & 57,400 & 4,200 \\
\hline
\end{tabular}

Table 2: Customer specific data

Survival ages were deduced from project experience and the data gathered. AVG failure duration was taken from VDN (2005), and Weibull parameters were estimated based on averages. Asset replacement cost can be found in Consentec et al. (2008, p. 113), and additional unplanned replacement costs were estimated at $20 \%$ of planned costs based on project experience. Penalties were calculated based on $€ 10 / \mathrm{kWh}$, customer-specific data in Table 2, average failure durations and assumptions concerning network structure and redundancy.

\begin{tabular}{|c|c|c|c|c|c|c|c|c|}
\hline Equipment & Unit & Transf. & $\mathbf{C B}$ & CMV & OLMV & REL & CLV & OHLV \\
\hline Optimal replacement & Years & 33 & 32 & 61 & 46 & 28 & 61 & 46 \\
\hline $80 \%$ survival age & Years & 25 & 25 & 40 & 35 & 25 & 40 & 35 \\
\hline $20 \%$ survival age & Years & 35 & 35 & 60 & 50 & 35 & 60 & 50 \\
\hline AVG failure duration & Min & 99 & 99 & 97 & 138 & 96 & 183 & 220 \\
\hline Failure duration (Weibull- $\alpha$ ) & - & 1.2 & 1.2 & 1.2 & 1.2 & 1.2 & 1.2 & 1.2 \\
\hline Failure duration (Weibull- $\beta$ ) & - & 104.80 & 104.80 & 102.27 & 146.97 & 102.48 & 195.42 & 238.18 \\
\hline Asset replacement cost & $€ \mathrm{~T}$ & 615 & 40 & $140 / \mathrm{km}$ & $30 / \mathrm{km}$ & 60 & $65 / \mathrm{km}$ & $25 / \mathrm{km}$ \\
\hline $\begin{array}{l}\text { Additional cost unplanned } \\
\text { replacement }\end{array}$ & $€ T$ & 123 & 8 & 28 & 6 & 12 & 13 & 5 \\
\hline Penalty/industry customer & $€$ & 49,452 & 49,452 & - & - & - & - & - \\
\hline $\begin{array}{l}\text { Penalty/commercial } \\
\text { customer }\end{array}$ & $€$ & 95 & 95 & 93 & 133 & 93 & 176 & 212 \\
\hline Penalty/household & $€$ & 7 & 7 & 6 & 9 & 7 & 12 & 15 \\
\hline
\end{tabular}

Table 3: Component specific data 


\section{REFERENCES}

Acharya, V., Almeida, H., \& Campello, M. (2007). A hedging perspective on corporate financial policies, Journal of Financial Intermediation, 16, 515-554.

Acharya, V., Almeida, H., \& Campello, M. (2009). Aggregate risk and the choice between cash and lines of credit. Working Paper, New York University.

Almeida, H., \& Philippon, T. (2007). The risk-adjusted cost of financial distress. The Journal of Finance, 62, 2557-2586.

ARegV (2012). Verordnung über die Anreizregulierung der Energieversorgungsnetze (Anreizregulierungsverordnung - ARegV). http://www.gesetze-im-internet.de/bundesrecht/aregv/gesamt.pdf. Accessed 25 March 2012.

Banz, R. W. (1981). The relationship between return and market value of common stocks. Journal of Financial Economics, 9, 3-18.

BDEW (2008). Nettostromverbrauch. www.bdew.de. Accessed 17 June 2009.

Billington, R. (2000). Methods to consider customer interruption costs in power system analysis. CIGRE Task Force 38.06.01, 38199.

BNetzA (2008). Monitoringbericht 2008. www.bundesnetzagentur.de. Accessed 28 September 2008.

Bradley, M., Jarrell, G. A., \& Kim, E. H. (1984). On the existence of an optimal capital structure: Theory and evidence. The Journal of Finance, 39, 857-878.

Brennan, M. J., \& Schwartz, E. S. (1982). Consistent regulatory policy under uncertainty. Bell Journal of Economics, 13, 506-521.

Bris, A., Welch, I., \& Zhu, N. (2006). The costs of bankruptcy. Journal of Finance, 61, 1253-1303.

Caillaud, B., Dionne, G., \& Jullien. B. (2000). Corporate insurance with optimal financial contracting. Economic Theory, 16, 77-105.

Consentec, IAEW, RZVN and Frontier Economics (2008). Untersuchung der Voraussetzungen und möglicher Anwendungen analytischer Kostenmodelle in der deutschen Energiewirtschaft. Untersuchung im Auftrag der Bundesnetzagentur, http://www.bundesnetzagentur.de/cln_1912/DE/ Sachgebiete/ElektrizitaetGas/Sonderthemen/sonderthemen_node.html. Accessed 25 November 2006.

Demiroglu, C., \& James, C. (2011). The use of bank lines of credit in corporate liquidity management: A review of empirical evidence. Journal of Banking \& Finance, 35, 775-782.

Densley, J. (2001). Ageing mechanisms and diagnostics for power cables - An overview. Electrical Insulation Magazine, IEEE, 17, 14-22.

Disatnik, D., Duchin, R., \& Schmidt B. (2010). Cash flow hedging and liquidity choices. Working Paper. http://ssrn.com/abstract=1442166. Accessed 18 February 2011.

Evans, L. T., \& Guthrie, G. A. (2005). Risk, price regulation, and irreversible investment. International Journal of Industrial Organization, 23, 109-128.

Fama, E. F., \& French, K. (1992). The cross-section of expected stock returns. The Journal of Finance, 47, 427465.

Fama, E. F., \& French, K. (1995). Size and book-to-market factors in earnings and returns. The Journal of Finance, 50, 131-155.

Fama, E. F., \& French, K. (1997). Industry costs of equity. Journal of Financial Economics, 43, $153-193$.

FGH (2006). Technischer Bericht 299 - Asset-Management von Verteilungsnetzen - Komponentenverhalten und Analyse des Kostenrisikos. Forschungsgemeinschaft für Elektrische Anlagen und Stromwirtschaft e. V.

Filippini, M., 1998, ‘Are Municipal Electricity Distribution Utilities Natural Monopolies?,' Annals of Public and Cooperative Economics, 69, pp. 157-174.

Flannery, M., \& Lockhart, B. (2009). Credit lines and the substitutability of cash and debt. Working Paper, University of Florida.

Frontier Economics (2008). Ermittlung des Zuschlags zur Abdeckung netzbetreiberspezifischer Wagnisse im Bereich Strom und Gas. Expertise for the German regulator BNetzA. http://www.bundesnetzagentur.de/SharedDocs/Downloads/DE/BNetzA/Sachgebiete/Energie/Sonderthe men/WagnisEigenkapitalverzinsung/GutachtenId13761pdf.pdf? blob=publicationFile. Accessed 17 April 2009.

Froot, K. A., Scharfstein, D. S., \& Stein, J. C. (1993). Risk management: Coordinating corporate investment and financing policies. Journal of Finance, 48, 1629-1658.

Froot, K. A., \& Stein, J. C. (1998). Risk management, capital budgeting, and capital structure policy for financial institutions: An integrated approach. Journal of Financial Economics, 47, 55-82.

Guthrie, G. A. (2005). Regulating infrastructure: The impact on risk and investment. Journal of Economic Literature, 54, 925-972. 
Holmström, B., \& Tirole, J. (1998). Private and public supply of liquidity. Journal of Political Economy, 106, 140.

Holmström, B., \& Tirole, J. (2000). Liquidity and risk management. Journal of Money, Credit and Banking, 32, 295-319.

Huettner, D. A., \& Landon, J. H. (1978). Electric utilities: Scale economies and diseconomies. Southern Economic Journal, 44, 883-912.

Kashyap, A., Rajan, R., \& Stein, J. (2002). Banks as liquidity providers: An explanation for the co-existence of lending and deposit-taking. Journal of Finance, 57, 33-73.

Lindquist, T., Bertling, L., \& Eriksson, R. (2008). Circuit-breaker failure data and reliability modelling. IET Generation, Transmission and Distribution.

Markowitz, H. (1952). Portfolio selection. Journal of Finance, 7, 77-91.

Obergünner, M. (2005). Bewertung und Optimierung des Instandhaltungsaufwands elektrischer Verteilungs netze. Aachener Beiträge zur Energieversorgung, 102, Appendix.

Opler, T. C., \& Titman, S. (1994). Financial distress and corporate performance. The Journal of Finance, 49, 1015-1040.

Reimund, C., Schwetzler, B., \& Zainhofer, F. (2008). Cost of financial distress: The German evidence. SSRN working paper series. http://papers.ssrn.com/sol3/papers.cfm?abstract_id=933567. Accessed 9 March 2009.

Roberts, A. (2001). Quality issues for system operators with special reference to European regulators. Brussels: Belgian Transmission System Operator (ELIA).

Roberts, M. E. (1998). Economies of density and size in the production and delivery of electric power. Land Economics, 62, 378-387.

Schaeffler, S. (2011). An evaluation of different approaches to capital structure regulation. Working Paper. http://www.ewl.wiwi.uni-due.de/forschung/ veroeffentlichungen/publikationen/. Accessed 20 October 2011.

Schaeffler, S., \& Weber, C. (2013). The cost of equity of network operators - Empirical evidence and regulatory practice. Journal of Competition and Regulation in Network Industries,14, 383-408.

Scherer, F. M., \& Ross, D. (1990). Industrial market structure and economic performance. 3rd ed. Boston: Houghton Mifflin (Academic).

Scott, J. H. (1976). A theory of optimal capital structure. The Bell Journal of Economics, 7, 33-54.

Sharpe, W. F. (1964). Capital asset prices: A theory of market equilibrium under conditions of risk. The Journal of Finance, 19, 425-442.

Shleifer, A., \& Vishny, R. W. (1992). Liquidation values and debt capacity: A market equilibrium approach. The Journal of Finance, 47, 1343-1366.

Smith, C., \& Stulz, R. (1985). The determinants of firms' hedging policies. Journal of Financial and Quantitative Analysis, 20, 391-405.

Stulz, R. (1984). Optimal hedging policies. Journal of Financial and Quantitative Analysis, 19, 127-140.

StromNEV (2011). Verordnung über die Entgelte für den Zugang zu Elektrizitätsversorgungsnetzen. www.bundesrecht.juris.de/stromnev/index.html. Accessed 2 December 2011.

Tirole, J. (2005) The theory of corporate finance. Princeton: Princeton University Press.

VDN (2005). VDN-Störungs- und Verfügbarkeitsstatistik. Verband der Netzbetreiber - VDN e.V. beim VDEW.

Weber, C., Schober, D., \& Schaeffler, S. (2010). Optimal replacement strategies in network infrastructures under quality penalties. Journal of Business Economics (Zeitschrift für Betriebswirtschaft), 80, 639-665. 